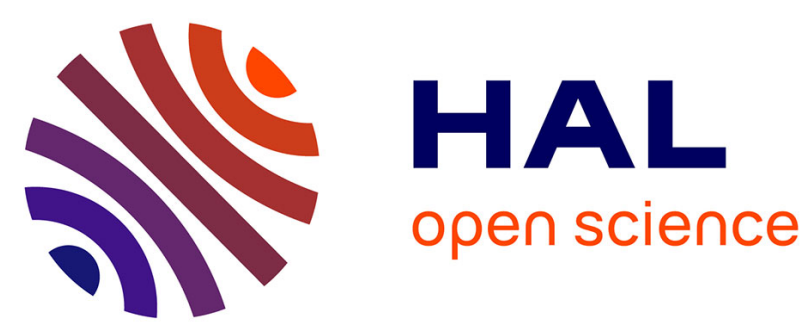

\title{
Dielectric Properties of Materials Showing Constant-Phase-Element (CPE) Impedance Response
} Mark E. Orazem, Isabelle Frateur, Bernard Tribollet, Vincent Vivier, Sabrina

Marcelin, Nadine Pébère, Annette L. Bunge, Erick A. White, Douglas P. Riemer, Marco Musiani

\section{To cite this version:}

Mark E. Orazem, Isabelle Frateur, Bernard Tribollet, Vincent Vivier, Sabrina Marcelin, et al.. Dielectric Properties of Materials Showing Constant-Phase-Element (CPE) Impedance Response. Journal of The Electrochemical Society, 2013, 160 (6), pp.C215-C225. 10.1149/2.033306jes . hal-00804229

\section{HAL Id: hal-00804229 \\ https://hal.sorbonne-universite.fr/hal-00804229}

Submitted on 9 Mar 2015

HAL is a multi-disciplinary open access archive for the deposit and dissemination of scientific research documents, whether they are published or not. The documents may come from teaching and research institutions in France or abroad, or from public or private research centers.
L'archive ouverte pluridisciplinaire HAL, est destinée au dépôt et à la diffusion de documents scientifiques de niveau recherche, publiés ou non, émanant des établissements d'enseignement et de recherche français ou étrangers, des laboratoires publics ou privés. 


\title{
Dielectric Properties of Materials showing Constant-Phase-Element (CPE) Impedance Response*
}

\author{
Mark E. Orazem, ${ }^{\mathrm{a}}$ Isabelle Frateur, ${ }^{\mathrm{b}}$ Bernard Tribollet, ${ }^{\mathrm{b}}$ \\ Vincent Vivier, ${ }^{\mathrm{b}}$ Sabrina Marcelin, ${ }^{\mathrm{c}}$ Nadine Pébère, ${ }^{\mathrm{c}}$ Annette L. Bunge, ${ }^{\mathrm{d}}$ \\ Erick A. White, ${ }^{\mathrm{d}}$ Douglas P. Riemer, ${ }^{\mathrm{e}}$ and Marco Musianif ${ }^{\mathrm{f}}$
}

a Department of Chemical Engineering, University of Florida, Gainesville, FL, 32611, USA

b LISE, UPR 15 du CNRS, Université P. et M. Curie, CP 133, 4 Place Jussieu, 75252 Paris cedex 05 France

c Université de Toulouse, CIRIMAT, UPS/INPT/CNRS, ENSIACET, 4, allée Emile Monso, BP 44362, 31030 Toulouse cedex 4, France

d Department of Chemical and Biological Engineering, Colorado School of Mines, Golden, CO 80401, USA

e Hutchinson Technology, Inc., 40 West Highland Park Dr. NE, Hutchinson, MN 55350, USA

f Istituto per l'Energetica e le Interfasi, IENI - CNR, Corso Stati Uniti 4, 35127 Padova, Italy

Key Words: effective capacitance, permittivity, oxides, human skin, membrane, film thickness

${ }^{*}$ Published in the Journal of The Electrochemical Society, 160 (2013), C215-C225 


\begin{abstract}
Constant-Phase Elements (CPE) are often used to fit impedance data arising from a broad range of experimental systems. Four approaches were used to interpret CPE parameters associated with the impedance response of human skin and two metal oxides in terms of characteristic frequencies and film thickness. The values obtained with each approach were compared against independent measurements. The power-law model developed recently by Hirschorn et al. ${ }^{1,2}$ provided the most reliable interpretation for systems with a normal distribution of properties. Readers are cautioned that the CPE parameter $Q$ does not provide an accurate value for capacitance, even when the CPE exponent is greater than 0.9 .
\end{abstract}

\title{
1 Introduction
}

Electrical circuits invoking constant-phase elements (CPE) are often used to fit impedance data arising from a broad range of experimental systems. The impedance for a film-covered electrode showing CPE behavior may be expressed in terms of ohmic resistance $R_{\mathrm{e}}$, a parallel resistance $R_{\|}$, and CPE parameters $\alpha$ and $Q$ as

$$
Z=R_{\mathrm{e}}+\frac{R_{\|}}{1+(\mathrm{j} 2 \pi f)^{\alpha} R_{\|} Q}
$$

where $f$ is the frequency in units of Hz. When $\alpha=1$, the system is described by a single time-constant, and the parameter $Q$ has units of capacitance; otherwise, $Q$ has units of $\mathrm{s}^{\alpha} / \Omega \mathrm{cm}^{2}$ or $\mathrm{F} / \mathrm{s}^{(1-\alpha)} \mathrm{cm}^{2}{ }^{3}$ Under conditions that $(2 \pi f)^{\alpha} R_{\|} Q>>1$,

$$
Z=R_{\mathrm{e}}+\frac{1}{(\mathrm{j} 2 \pi f)^{\alpha} Q}
$$

which has the appearance of a blocking electrode. The term $R_{\|}$in equation (1) accounts for a resistance that may be attributed to different current pathways that exist in parallel to the dielectric response of a film. These may include interconnecting conductive phases within a solid matrix or pores at the bottom of which a reaction takes place at the electrolyte/metal interface.

Jorcin et al. ${ }^{4}$ used Local Electrochemical Impedance Spectroscopy (LEIS) to attribute CPE behavior, seen in the global measurements, to time-constants that are distributed either along the electrode surface or in the direction perpendicular (or normal) to the electrode surface. Normal distributions of time-constants can be expected in systems such as oxide films, organic coatings, and human skin and can be associated with the dielectric properties of a material. Surface distributions of film properties may also be expected. In the absence of additional information, such as may be obtained from local impedance measurements, one cannot conclude a priori whether CPE behavior associated with film-covered electrodes or membranes should be attributed to normal or surface distributions.

If the CPE impedance response can be associated with an effective capacitance, the dielectric constant or the film thickness may be obtained from

$$
C_{\text {eff }}=\frac{\epsilon \epsilon_{0}}{\delta}
$$


when the other quantity is known. In equation (3), $\delta$ is the film thickness, $\epsilon$ is the dielectric constant, and $\epsilon_{0}$ is the permittivity of vacuum with a value of $\epsilon_{0}=$ $8.8542 \times 10^{-14} \mathrm{~F} / \mathrm{cm}$.

The challenge has been to find a correct way to extract an effective capacitance from CPE parameters. The objective of this work is to compare the results obtained from four different approaches to independently measured quantities.

\section{The Approaches}

Four approaches used in the literature for extracting capacitance from CPE parameters are summarized in this section: simply equating $C_{\text {eff }}$ to $Q$, a formula developed by Brug et al., ${ }^{5}$ a formula derived from the work of Hsu and Mansfeld, ${ }^{6}$ and a model presented by Hirshorn et al. ${ }^{1,2}$

Other methods have been used to extract capacitance values directly from impedance data without initial evaluation in terms of a CPE. The formula used by Oh and $\mathrm{Guy}^{7,8}$ was

$$
C_{\text {eff }, \text { OG }}=\frac{\tan \theta_{\mathrm{c}, \text { norm }}}{2 \pi R_{\|} f_{\mathrm{c}, \text { norm }}}
$$

where $\theta_{c, n o r m}$ is the phase angle at the characteristic frequency for the impedance, $f_{\mathrm{c}, \text { norm }}$. Equation (4) can be expressed as

$$
C_{\text {eff, OG }}=\frac{\tan (\alpha \pi / 4)}{2 \pi R_{\|} f_{\mathrm{c}, \text { norm }}}
$$

and is mathematically equivalent to equation (11) (see below) multiplied by $\tan (\alpha \pi / 4)$. As the methods reported in references 7 and 8 do not make use of CPE parameters, they are not discussed further in the present work.

\subsection{Simple Substitution}

In this approach $C_{\text {eff }}$, expressed in units of $\mathrm{F} / \mathrm{cm}^{2}$, is assigned the value of $Q$, expressed in units of $\mathrm{F} / \mathrm{s}^{(1-\alpha)} \mathrm{cm}^{2}$, while ignoring the difference in units. Thus, the approach consists of positing that

$$
C_{\text {eff }, Q}=Q
$$

This approach, often used when $1>\alpha>0.9$, is inaccurate and, as shown in the present work, should be avoided.

\subsection{Characteristic Frequency Associated with a Normal Distribution}

As shown by Hirschorn et al., ${ }^{9}$ the relationship between CPE parameters and effective capacitance for a normal distribution of time constants requires an assessment of the characteristic time constant corresponding to the impedance of the film. The impedance of a film can be expressed in terms of a CPE by equation (1) where $R_{\|}$ represents the parallel resistance. Alternatively,

$$
Z=R_{\mathrm{e}}+\frac{R_{\|}}{1+\left(\mathrm{j} K_{\mathrm{norm}}\right)^{\alpha}}
$$


where $K_{\text {norm }}$ is a dimensionless frequency which can be expressed for an impedance as

$$
K_{\text {norm }}=\left(R_{\|} Q\right)^{1 / \alpha} 2 \pi f
$$

A characteristic frequency can be found for $K_{\text {norm }}=1$ such that

$$
f_{\mathrm{c}, \mathrm{norm}}=\frac{1}{2 \pi\left(R_{\|} Q\right)^{1 / \alpha}}
$$

The essential hypothesis of the approach presented in this section is that the characteristic frequency can also be expressed in terms of an effective capacitance as

$$
f_{\mathrm{c}, \text { norm }}=\frac{1}{2 \pi R_{\|} C_{\text {eff, norm }}}
$$

By solving equations (9) and (10) for $C_{\text {eff,norm, }}$, an expression for the effective capacitance associated with the CPE is found to be

$$
C_{\text {eff }, \text { norm }}=Q^{1 / \alpha} R_{\|}^{(1-\alpha) / \alpha}
$$

Equation (11) is equivalent to equation (3) in the work of Hsu and Mansfeld, ${ }^{6}$ presented in terms of the characteristic angular frequency $\omega_{\max }$.

\subsection{Characteristic Frequency Associated with a Surface Distribution}

In the case of a surface time-constant distribution, the global admittance response of the electrode includes additive contributions from each part of the electrode surface. Hirschorn et al. ${ }^{9}$ showed the development of a relationship between capacitance and CPE parameters for a surface distribution of time constants. In agreement with Chassaing et al. ${ }^{10}$ and Bidóia et al., ${ }^{11}$ they observed that the appearance of a CPE behavior associated with a surface distribution of time constants requires the contribution of an ohmic resistance.

The development of Brug et al. ${ }^{5}$ was applied toward surface distributions of the charge transfer resistance $R_{\mathrm{t}}$ associated with kinetic parameters. In the present

work, the same approach is applied for a surface distribution for the properties of a film such as its parallel resistance $R_{\|}$or capacitance. The relationship between CPE parameters and effective capacitance is obtained from the characteristic time constant associated with the admittance of the electrode. The admittance of the electrode can be expressed in terms of the CPE represented by equation (1) as

$$
Y=\frac{1}{R_{\mathrm{e}}}\left[1-\frac{R_{\|}}{R_{\mathrm{e}}+R_{\|}}\left(1+\frac{R_{\mathrm{e}} R_{\|}}{R_{\mathrm{e}}+R_{\|}} Q(\mathrm{j} 2 \pi f)^{\alpha}\right)^{-1}\right]
$$

Equation (12) can be expressed as

$$
Y=\frac{1}{R_{\mathrm{e}}}\left[1-\frac{R_{\|}}{R_{\mathrm{e}}+R_{\|}}\left(1+\left(\mathrm{j} K_{\text {surf }}\right)^{\alpha}\right)^{-1}\right]
$$


where $K_{\text {surf }}$ is a dimensionless frequency, expressed for an admittance as

$$
K_{\text {surf }}=\left(\frac{R_{\mathrm{e}} R_{\|}}{R_{\mathrm{e}}+R_{\|}} Q\right)^{1 / \alpha} 2 \pi f
$$

A characteristic frequency can be found for $K_{\text {surf }}=1$ such that

$$
f_{\mathrm{c}, \text { surf }}=\frac{1}{2 \pi\left(Q R_{\mathrm{e}} R_{\|} /\left(R_{\mathrm{e}}+R_{\|}\right)\right)^{1 / \alpha}}
$$

This frequency depends on the ohmic and parallel resistances as well as the CPE parameters. When $R_{\mathrm{e}}=0$, the development yields the response of an ideal capacitance parallel to a resistance, and $f_{\mathrm{c}, \text { surf }} \rightarrow \infty$.

The characteristic frequency can also be expressed in terms of an effective capacitance as

$$
f_{\mathrm{c}, \text { surf }}=\frac{1}{2 \pi\left(\frac{R_{\mathrm{e}} R_{\|}}{R_{\mathrm{e}}+R_{\|}} C_{\mathrm{eff}, \text { surf }}\right)}
$$

Equations (15) and (16) yield an expression for the effective capacitance as

$$
C_{\text {eff,surf }}=Q^{1 / \alpha}\left(\frac{R_{\mathrm{e}} R_{\|}}{R_{\mathrm{e}}+R_{\|}}\right)^{(1-\alpha) / \alpha}
$$

Equation (17) is equivalent to equation (20) derived by Brug et al. ${ }^{5}$ for a surface distribution with a different definition of CPE parameters. In the limit that $R_{\|}$ becomes much larger than $R_{\mathrm{e}}$, equation (17) becomes

$$
C_{\text {eff }, \text { surf }}=Q^{1 / \alpha} R_{\mathrm{e}}^{(1-\alpha) / \alpha}
$$

which is equivalent to equation (5) presented by Brug et al. ${ }^{5}$ for a blocking electrode.

Equations (17), (18), and (11) have all the same form, but the resistance used in the calculations of $C_{\text {eff }}$ is different in the three cases, being respectively the parallel combination of $R_{\|}$and $R_{\mathrm{e}}$ for equation (17), $R_{\mathrm{e}}$ for equation (18) and $R_{\|}$for equation (11).

\subsection{Power-Law Distribution}

Hirschorn et al. ${ }^{1,2}$ identified a relationship between CPE parameters and physical properties by regressing a measurement model ${ }^{12,13}$ to synthetic CPE data. Following the procedure described by Agarwal et al., ${ }^{12,13}$ sequential Voigt elements were added to the model until the addition of an element did not improve the fit and one or more model parameters included zero within their 95.4 percent $(2 \sigma)$ confidence interval.

The concept was to identify the distribution of resistivity that, under the assumption that the dielectric constant is independent of position, would result in CPE behavior. The development is presented in detail in reference 1 . The assumption of a uniform dielectric constant is not critical to the development summarized below. Musiani et al. ${ }^{14}$ have shown that the results presented by Hirschorn et al. ${ }^{1,2}$ apply, 
even when the assumption of a uniform dielectric constant is relaxed by allowing variation of $\epsilon$ in the region of low resistivity.

The resistivity was found to follow a power-law profile, i.e.,

$$
\frac{\rho}{\rho_{\delta}}=\xi^{-\gamma}
$$

where $\xi$ is the dimensionless position $\xi=y / \delta$, where $y$ represents the position through the depth of the film and $\delta$ is the film thickness. The parameter $\rho_{\delta}$ is the resistivity at $\xi=1$, and $\gamma$ is a constant indicating how sharply the resistivity varies. A distribution of resistivity that provides a bounded value for resistivity was proposed to be

$$
\frac{\rho}{\rho_{\delta}}=\left(\frac{\rho_{\delta}}{\rho_{0}}+\left(1-\frac{\rho_{\delta}}{\rho_{0}}\right) \xi^{\gamma}\right)^{-1}
$$

where $\rho_{0}$ and $\rho_{\delta}$ are the boundary values of resistivity at the interfaces.

The impedance of the film can be written for an arbitrary resistivity distribution $\rho(y)$ as

$$
Z_{\mathrm{f}}(f)=\int_{0}^{\delta} \frac{\rho(y)}{1+\mathrm{j} 2 \pi f \epsilon \epsilon_{0} \rho(y)} d y
$$

A semi-analytic solution to equation (21) could be found for the resistivity profile given in equation (20) that applied under the conditions that $\rho_{0}>>\rho_{\delta}$ and $f<$ $\left(2 \pi \rho_{\delta} \epsilon \epsilon_{0}\right)^{-1}$. The solution was given as

$$
Z_{\mathrm{f}}(f)=g \frac{\delta \rho_{\delta}^{1 / \gamma}}{\left(\rho_{0}^{-1}+\mathrm{j} 2 \pi f \epsilon \epsilon_{0}\right)^{(\gamma-1) / \gamma}}
$$

where $g$ is a function of $\gamma$.

Equation (22) is in the form of the CPE for $f>\left(2 \pi \rho_{0} \epsilon \epsilon_{0}\right)^{-1}$, i.e.,

$$
Z_{\mathrm{f}}(f)=g \frac{\delta \rho_{\delta}^{1 / \gamma}}{\left(\mathrm{j} 2 \pi f \epsilon \epsilon_{0}\right)^{(\gamma-1) / \gamma}}=\frac{1}{(\mathrm{j} 2 \pi f)^{\alpha} Q}
$$

Thus, equation (22) yields the impedance given by the ohmic-resistance-compensated form of equation (2) for $\left(\rho_{0} \epsilon \epsilon_{0}\right)^{-1}<2 \pi f<\left(\rho_{\delta} \epsilon \epsilon_{0}\right)^{-1}$. Inspection of equation (23) suggests that

$$
\alpha=\frac{\gamma-1}{\gamma}
$$

or $1 / \gamma=1-\alpha$ where $\gamma \geq 2$ for $0.5 \leq \alpha \leq 1$. Numerical integration was used to develop the interpolation formula

$$
g=1+2.88(1-\alpha)^{2.375}
$$

A relationship among the CPE parameters $Q$ and $\alpha$ and the dielectric constant $\epsilon$, resistivity $\rho_{\delta}$, and film thickness $\delta$ was found to be

$$
Q=\frac{\left(\epsilon \epsilon_{0}\right)^{\alpha}}{g \delta \rho_{\delta}^{1-\alpha}}
$$


Equations (3) and (26) yield an expression for the effective capacitance as

$$
C_{\text {eff,PL }}=g Q\left(\rho_{\delta} \epsilon \epsilon_{0}\right)^{1-\alpha}
$$

In addition to the CPE parameters $Q$ and $\alpha, C_{\text {eff,PL }}$ depends on the dielectric constant $\epsilon$ and the smaller value of the resistivity $\rho_{\delta}$. Unlike the development for $C_{\text {eff,surf }}$ and $C_{\text {eff,norm }}$, the characteristic frequency is not invoked, and, in contrast with $C_{\text {eff,norm }}$, the results depend only on the high-frequency data.

Equation (27) can also be expressed as

$$
C_{\text {eff,PL }}=(g Q)^{1 / \alpha}\left(\delta \rho_{\delta}\right)^{(1-\alpha) / \alpha}
$$

which shows a similar construction as equation (11) and equations (17) and (18). The difference between the approaches based on the power-law and the characteristic frequency of the impedance is that the resistance $\delta \rho_{\delta}$ is related to the high-frequency portion of the spectrum; whereas, the resistance $R_{\|}$in equation (11) is associated with the low-frequency part of the spectrum.

The power-law model presented here suggests that the characteristic frequency of the impedance cannot give a correct value for the capacitance. An explanation may be seen from the hierarchy presented in Figure 1 of impedance models based on the power-law model. ${ }^{1,2}$ The circuit presented in Figure 1(a), showing a resistance in parallel to the dielectric response of the film given by equation (22), represents a general model for the response of a film. If the parallel resistance is larger than the zero-frequency limit of equation (22), the model will be given by Figure 1(b), and the impedance response shown in Figure 1(c) will be asymmetric in a Nyquist format. If the parallel resistance is smaller than the zero-frequency limit of equation (22), the model will be given by Figure 1(d), and the impedance response shown in Figure 1(e) will be symmetric in a Nyquist format.

The demonstration given in Figure 1 is based on the power-law model for the dielectric response of a material. The applicability of the power-law model is supported by experimental data obtained for human skin and oxides on steel (shown in the present work), and by recent results on water uptake of coatings. ${ }^{15}$

If the impedance is symmetric, the resistance $R_{\|}$in Figure 1(d) accounts for processes that are parallel to the dielectric response of the film. The effective capacitance of the dielectric material, in this case, is independent of the parallel resistance. If the impedance is asymmetric, as is seen for Figure $1(\mathrm{c}), Z_{\mathrm{f}}(0)$ may be more closely related to the dielectric properties, but a deeper analysis of the consequences of the power-law model shows that the capacitance is independent of this parameter. Introduction of equations (24) into equation (22) yields ${ }^{2}$

$$
Z_{\mathrm{f}}(f)=g \frac{\delta \rho_{\delta}^{(1-\alpha)}}{\left(\rho_{0}^{-1}+\mathrm{j} 2 \pi f \epsilon \epsilon_{0}\right)^{\alpha}}
$$

The asymptotic value of equation (29) as $f \rightarrow 0$ yields

$$
Z_{\mathrm{f}}(0)=g \delta \rho_{\delta}^{(1-\alpha)} \rho_{0}^{\alpha}
$$

which may be used to obtain a value for $\rho_{0}$. The capacitance given by equation (27) is independent of $\rho_{0}$ and is, therefore, independent of $Z_{\mathrm{f}}(0)$. 


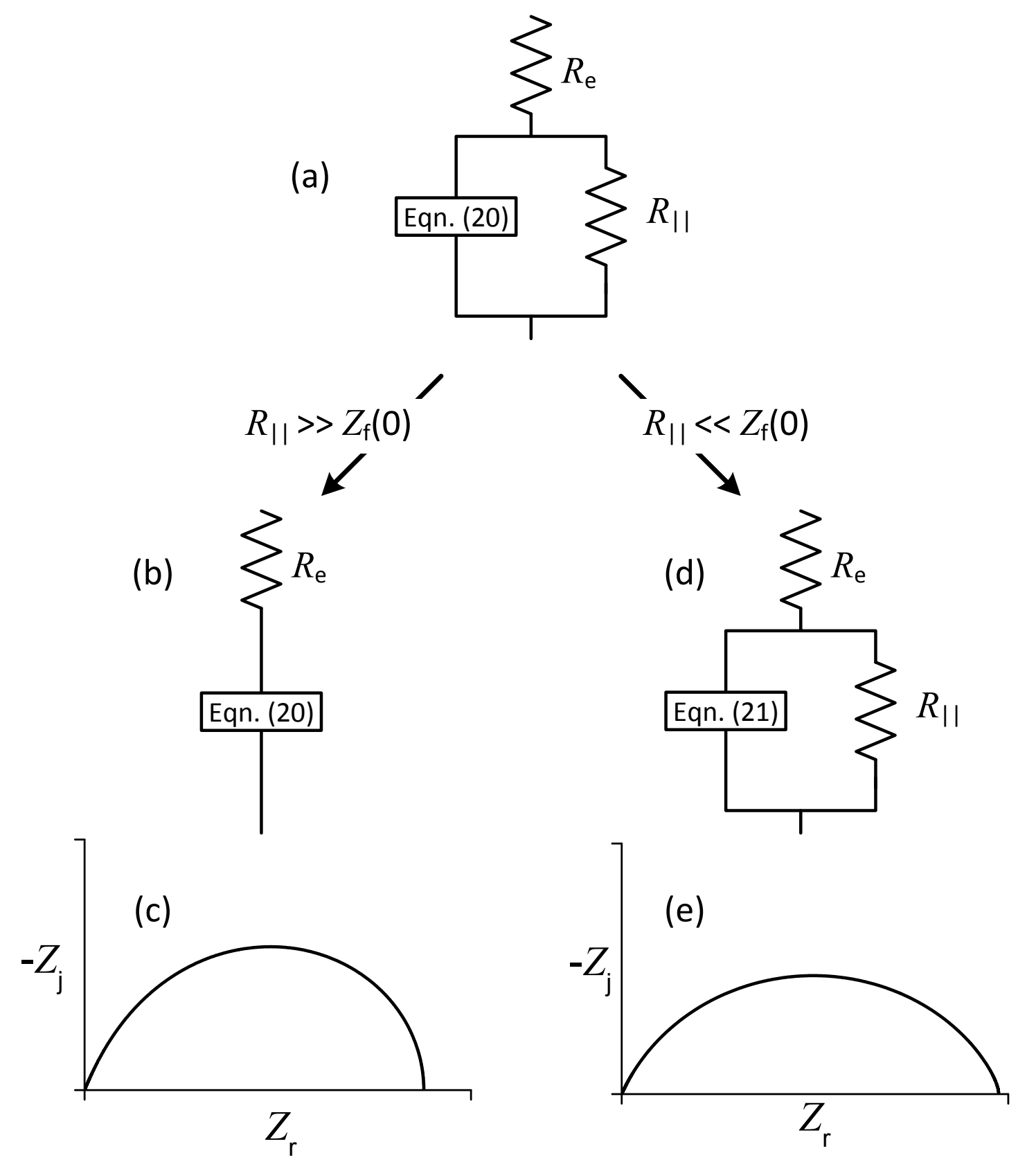

Figure 1: Hierarchy of impedance models based on the power-law model: ${ }^{1,2}$ a) circuit consisting of a resistance in parallel with the general power-law model expressed as equation (22); b) circuit resulting when $R_{\|}$is much larger than the zero-frequency limit of equation (22); c) Nyquist representation of the asymmetric impedance resulting from circuit b; d) circuit resulting when $R_{\|}$is much smaller than the zerofrequency limit of equation (22), thus allowing equation (22) to be replaced by equation (23); and e) Nyquist representation of the symmetric impedance resulting from circuit d. 
Table 1: Approaches used in the present work to interpret CPE impedance response for film-covered electrodes and human skin.

\begin{tabular}{l|c|c}
\hline Approach & Formula & Eqn. \\
\hline Simple Substitution & $C_{\mathrm{eff}, Q}=Q$ & $(6)$ \\
Characteristic Frequency, Impedance & $C_{\mathrm{eff}, \mathrm{norm}}=Q^{1 / \alpha} R_{\|}^{(1-\alpha) / \alpha}$ & $(11)$ \\
Characteristic Frequency, Admittance & $C_{\text {eff,surf }}=Q^{1 / \alpha}\left(\frac{R_{\mathrm{e}} R_{\|}}{R_{\mathrm{e}}+R_{\|}}\right)^{(1-\alpha) / \alpha}$ & $(17)$ \\
Power-Law Normal Distribution & $C_{\mathrm{eff}, \mathrm{PL}}=g Q\left(\rho_{\delta} \epsilon \epsilon_{0}\right)^{1-\alpha}$ & $(27)$ \\
& $C_{\text {eff,PL }}=(g Q)^{1 / \alpha}\left(\delta \rho_{\delta}\right)^{(1-\alpha) / \alpha}$ & $(28)$ \\
\hline
\end{tabular}

\section{Results}

The formulae presented in the previous section and summarized in Table 1 are applied here for three different systems. In-vitro impedance data for intact human skin and for skin pierced by a needle reveal a shift in characteristic frequency which can be used to differentiate between equations (11), (17), and (27). The four approaches summarized in Table 1 are used to estimate the oxide film thickness for free-machining 18/8 stainless steel and for martensitic steel. The results are compared to thicknesses determined by XPS.

\subsection{Human Skin}

The results reported in the present work for the influence of mechanical disruption to the impedance of human skin were part of a larger study intended to correlate changes in the flux of p-chloronitrobenzene and 4-cyanophenol in response to physical and chemical damage. ${ }^{16-19}$ Split-thickness human cadaver skin (300-400 $\mu$ m thick) from the back was purchased from the National Disease Research Interchange (NDRI, Philadelphia, PA). The skin was collected within $24 \mathrm{~h}$ post mortem, frozen immediately, and stored at temperatures less than $-60{ }^{\circ} \mathrm{C}$ until used. The protocol described by White et al. ${ }^{17}$ was used to ensure that the skin resistance was greater than $20 \mathrm{k} \Omega \mathrm{cm}^{2}$, a value considered to indicate that samples have sufficient integrity for meaningful measurements of in-vitro chemical permeability.

The impedance was measured in the four-electrode configuration, illustrated in Figure 2(a), in which two $\mathrm{Ag} / \mathrm{AgCl}$ (In Vivo Metric, Healdsburg, CA) reference electrodes were used to sense the potential drop across the skin, and two $\mathrm{Ag} / \mathrm{AgCl}$ working electrodes were used to drive the current. The skin was exposed on both sides for roughly eight hours to a phosphate buffered saline solution (PBS) (0.01 M, pH 7.4, Sigma P-3813) prepared in de-ionized water. The impedance measurements reported here were collected with a $10 \mathrm{mV}$ potential perturbation after two eight-hour long, permeation experiments in which 4-cyanophenol-saturated PBS was placed in the donor chamber and PBS was placed in the receptor chamber. After the first 4-cyanophenol permeation experiment, the frame holding the skin was removed from the diffusion cell, the skin was pierced by a 26 gauge needle (with a $464 \mu \mathrm{m}$ outside diameter), the cell was reassembled, and the donor and receptor chambers refilled 


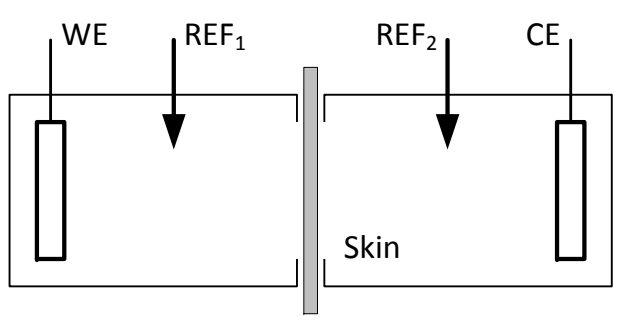

(a)

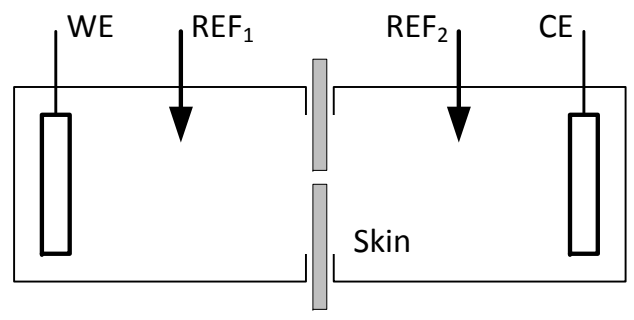

(b)

Figure 2: Schematic representation of the measurement of skin impedance: a) fourelectrode measurement with intact piece of skin; and b) four-electrode measurement with skin punctured by a needle.

with fresh 4-cyanophenol-saturated PBS and PBS, respectively, for the second permeation experiment. Typical results, presented in Figure 3, show that the characteristic frequency before the puncture was substantially smaller than the characteristic frequency after the puncture. The lines represent fits to the circuit presented in Figure 4(a) as the circuits 4(a) and 4(b) are mathematically equivalent. For a skin pierced by the needle, the parameter $R_{\text {skin,\| }}$ in Figure $4(\mathrm{a})$ is replaced by

$$
R_{\text {eff }}=\frac{R_{\text {skin, } \|} R_{\text {hole }}}{R_{\text {skin, } \|}+R_{\text {hole }}}
$$

The values of $R_{\text {skin,|| }}$ and $R_{\text {hole }}$ cannot be distinguished from an individual impedance response. As indicated by the circuit shown in Figure 4(b), the effective resistance associated with the punctured skin consists of two parts, the hole resistance and the skin resistance.

Because the diameter of the needle used to puncture the skin was small compared to the total skin area, the pinhole was expected to have little effect on the impedance properties of the remaining skin. Control experiments were used to show that the electrical properties of skin were unaffected by other skin handling steps. Therefore, the skin resistance and the dielectric constant for the skin were assumed to be the same before and after the skin was pierced by the needle.

The regression results are presented in Table 2 for seven skin samples, with measurements taken before and after the skin was pierced by a needle. The results show that the resistance $R_{\text {eff }}$, for the pierced skin, was much smaller than $R_{\text {skin, }}$, and the corresponding characteristic frequency was larger. The average of all seven samples is also shown in Table 2. The averaged ratio of characteristic frequencies before and after the skin was pierced by a needle had a value $f_{\text {after }} / f_{\text {before }}=13$.

If the capacitance $C_{\text {eff,norm }}$ derived from the characteristic frequency $f_{\text {c,norm }}$ and given by equation (11) represents a fundamental property of the skin, then

$$
C_{\text {skin }}=C_{\text {eff,norm }}=\frac{\epsilon \epsilon_{0}}{\delta}=\text { constant }
$$

and, following equation (10),

$$
\frac{f_{\text {after }}}{f_{\text {before }}}=\frac{C_{\text {eff,norm }} R_{\text {before }}}{C_{\text {eff,norm }} R_{\text {after }}}=\frac{R_{\text {before }}}{R_{\text {after }}}
$$




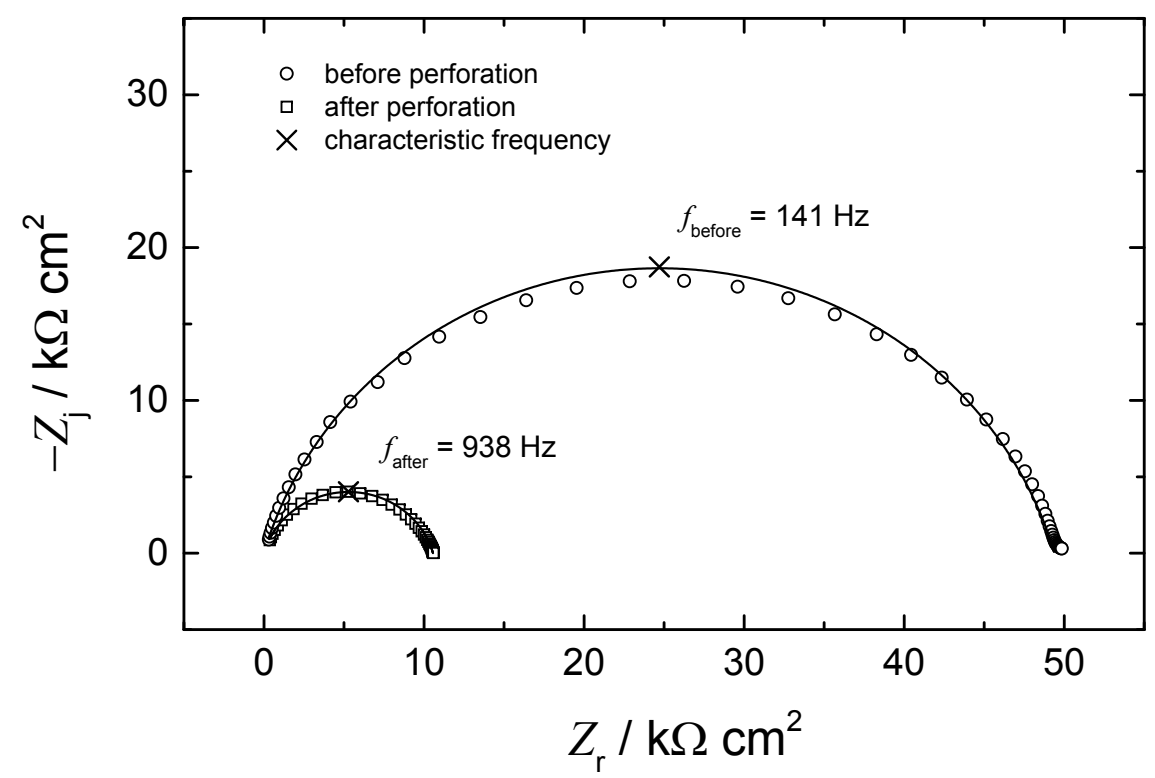

(a)

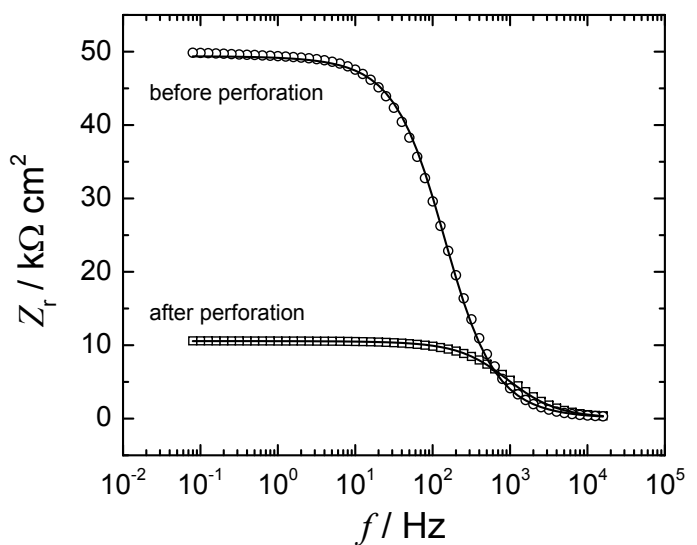

(b)

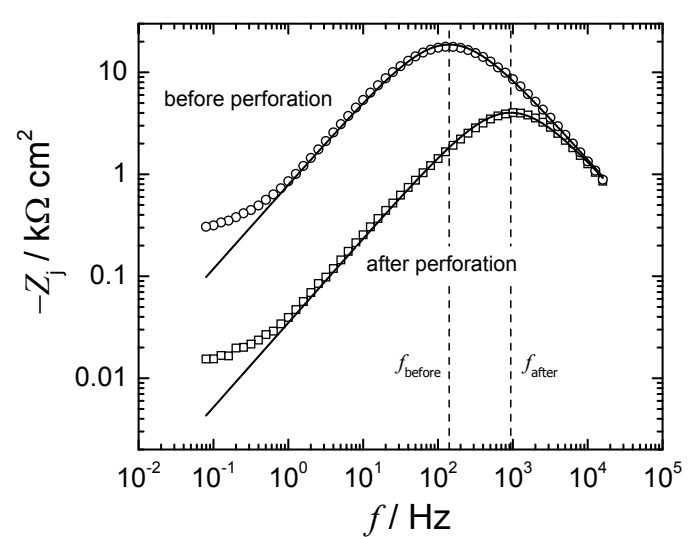

(c)

Figure 3: Impedance response for a representative piece of skin: a) Nyquist plot; b) real part of the impedance as a function of frequency; and c) imaginary part of the impedance as a function of frequency. 


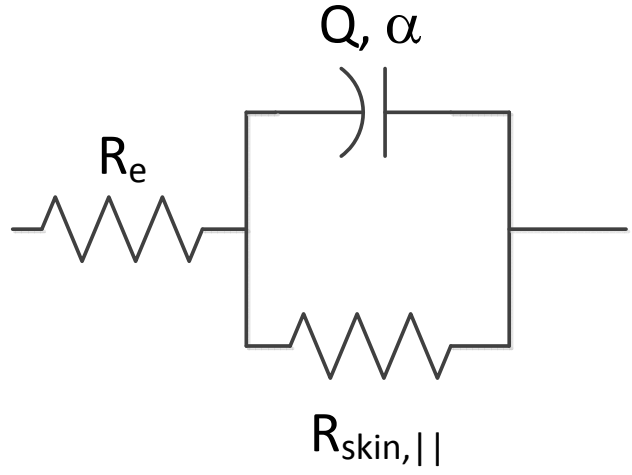

(a)

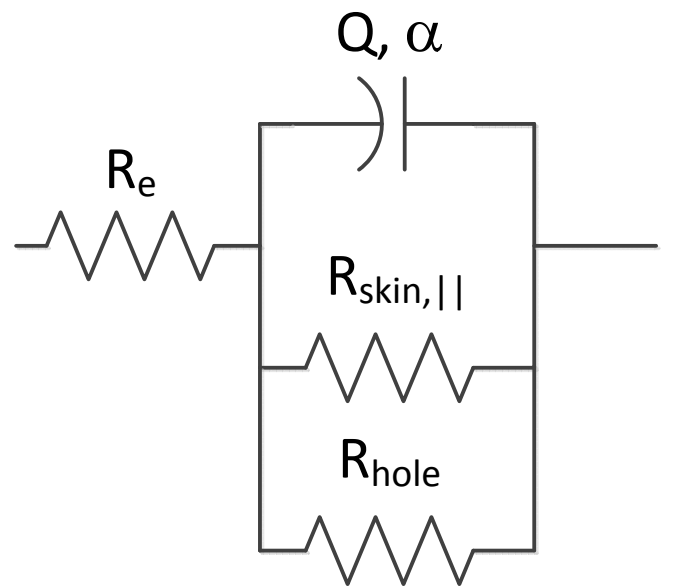

(b)

Figure 4: Electrical circuits used to fit the data shown in Figure 3: a) intact piece of skin; and b) punctured by a needle. The term $R_{\mathrm{e}}$ accounts for electrolyte resistance on both sides of the skin.

Table 2: Regression results for the impedance of skin before and after being pierced by a needle. The number of digits given in the regression results are consistent with the corresponding confidence interval.

\begin{tabular}{c|cc|cc|cc|cc}
\hline & \multicolumn{2}{|c|}{ Sample 1 } & \multicolumn{2}{c|}{ Sample 2 } & \multicolumn{2}{c|}{ Sample 3 } & \multicolumn{2}{c}{ Sample 4 } \\
\hline & before & after & before & after & before & after & before & after \\
\hline$R_{\text {skin }, \| \text { or } R_{\text {eff }}, \mathrm{k} \Omega \mathrm{cm}^{2}}$ & 141.8 & 9.94 & 93.6 & 24.1 & 93.4 & 15.96 & 55.2 & 11.78 \\
$\alpha$ & 0.81 & 0.82 & 0.82 & 0.82 & 0.79 & 0.82 & 0.83 & 0.83 \\
$Q, \mathrm{nF} / \mathrm{s}^{(1-\alpha)} \mathrm{cm}^{2}$ & 79.8 & 67.7 & 68.5 & 73.5 & 99.7 & 83.0 & 66.5 & 63.7 \\
$f_{\mathrm{c}}, \mathrm{Hz}$ & 41 & 1117 & 74 & 364 & 59 & 528 & 141 & 938 \\
\hline & \multicolumn{2}{|c|}{ Sample 5 } & \multicolumn{2}{|c|}{ Sample 6} & \multicolumn{2}{|c|}{ Sample 7} & \multicolumn{2}{c}{ All Samples } \\
\hline & before & after & before & after & before & after & before & after \\
\hline$R_{\text {skin, }, \| \text { or } R_{\text {eff }}, \mathrm{k} \Omega \mathrm{cm}^{2}}$ & 179 & 15.63 & 192 & 21.20 & 68.8 & 14.88 & $\mathbf{1 1 8}$ & $\mathbf{1 6 . 2}$ \\
$\alpha$ & 0.83 & 0.85 & 0.81 & 0.84 & 0.82 & 0.83 & $\mathbf{0 . 8 2}$ & $\mathbf{0 . 8 3}$ \\
$Q, \mathrm{nF} / \mathrm{s}^{(1-\alpha)} \mathrm{cm}^{2}$ & 61.8 & 51.3 & 70.5 & 57.3 & 73.1 & 69.5 & $\mathbf{7 4 . 3}$ & $\mathbf{6 6 . 6}$ \\
$f_{\mathrm{c}}, \mathrm{Hz}$ & 37 & 721 & 31 & 477 & 99 & 648 & $\mathbf{6 8 . 9}$ & $\mathbf{6 8 5}$ \\
\hline
\end{tabular}




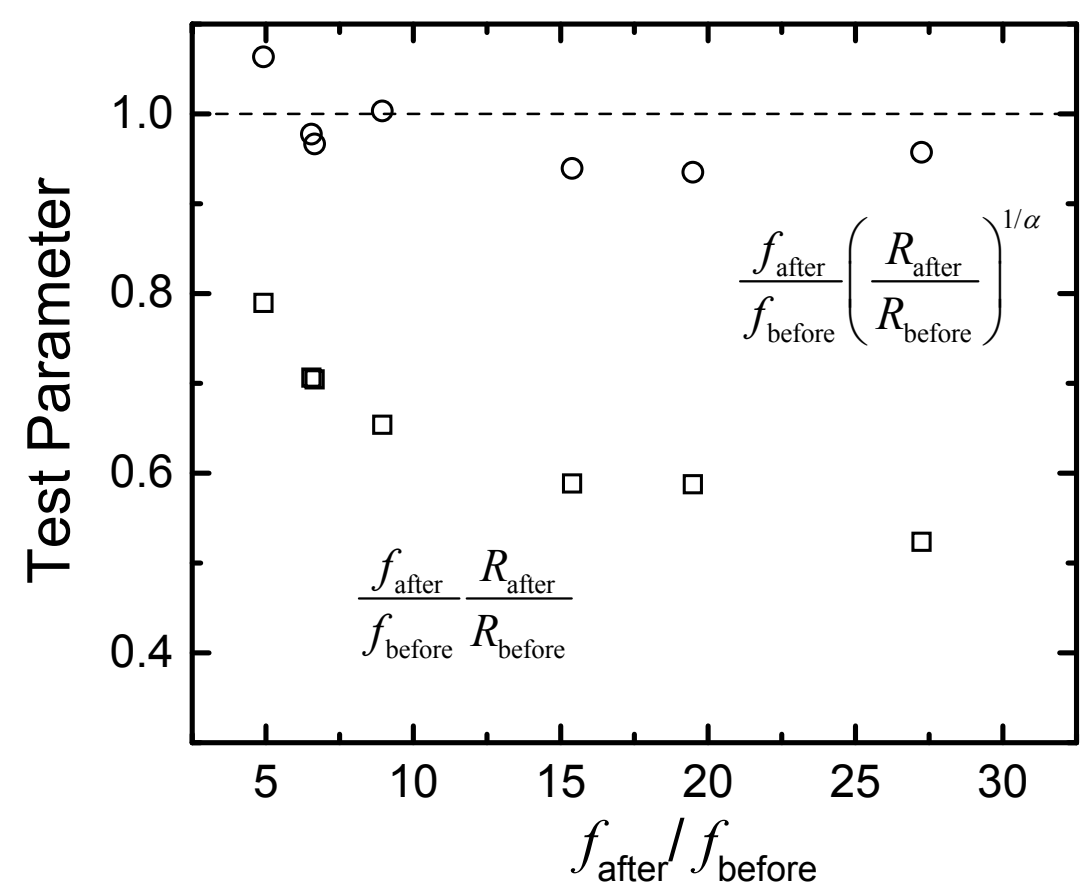

Figure 5: A test of the hypotheses that the capacitance of the skin can be obtained from the characteristic frequency $f_{\mathrm{c}, \text { norm }}$, given as equation (11), and from the powerlaw distribution of resistivity, given as equation (27): $\square$ test of equation (34); $\bigcirc$ test of equation (38).

Equation (33) can be expressed as

$$
\frac{f_{\text {after }} R_{\text {after }}}{f_{\text {before }} R_{\text {before }}}=1
$$

As shown in Figure $5, f_{\text {after }} R_{\text {after }} / f_{\text {before }} R_{\text {before }}$ is not equal to unity. Thus, the capacitance $C_{\text {eff,norm }}$ derived from the characteristic frequency $f_{\mathrm{c}, \text { norm }}$ does not represent a fundamental property of the skin.

A second approach invokes the assumption that the CPE behavior for skin may be attributed to a surface distribution of properties. Because both $R_{\text {skin,\|l }}$ and $R_{\text {eff }}$ are much greater than the ohmic resistance $R_{\mathrm{e}}$, the characteristic frequency obtained from a surface distribution (equation (15)) becomes

$$
f_{\mathrm{c}, \mathrm{surf}}=\frac{1}{2 \pi\left(Q R_{\mathrm{e}}\right)^{1 / \alpha}}
$$

Under the assumptions that $R_{\mathrm{e}}, Q$, and $\alpha$ were unchanged by the perforation of the skin, equation (35) yields

$$
\frac{f_{\text {after }}}{f_{\text {before }}}=1
$$

Thus, the surface distribution model predicts incorrectly that the characteristic frequency should be unchanged by skin perforation.

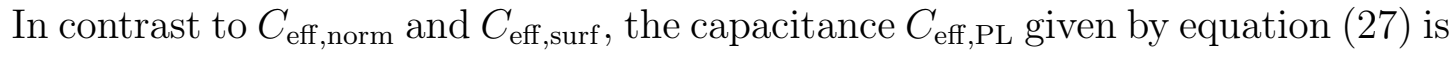
independent of the characteristic frequency. As a third approach, $C_{\text {eff,PL was assumed }}$ 
to be a property of the skin and, thus, was assumed to be independent of the presence of the pinhole. As $\rho_{\delta}$ and $\epsilon$ must be properties of the skin and therefore constant, equation (27) suggests that the CPE parameters $Q$ and $\alpha$ must be constant and not influenced by the small pinhole. In this case, from equation (9),

$$
\frac{f_{\text {after }}}{f_{\text {before }}}=\left(\frac{Q_{\text {before }} R_{\text {before }}}{Q_{\text {after }} R_{\text {after }}}\right)^{1 / \alpha}=\left(\frac{R_{\text {before }}}{R_{\text {after }}}\right)^{1 / \alpha}
$$

Equation (37) can be expressed as

$$
\frac{f_{\text {after }}}{f_{\text {before }}}\left(\frac{R_{\text {after }}}{R_{\text {before }}}\right)^{1 / \alpha}=1
$$

As shown in Figure $5,\left(f_{\text {after }} / f_{\text {before }}\right)\left(R_{\text {after }} / R_{\text {before }}\right)^{1 / \alpha}$ is equal to unity. Thus, the results for skin are consistent with the power-law model represented by equation (27).

The results are inconsistent with approaches based on characteristic frequencies because, as indicated by equation (31), the characteristic frequency is affected by factors, such as the hole resistance, that are not properties of the skin. The analysis of the data obtained with human skin shows that the capacitance is independent of the low-frequency asymptotic value for resistance and depends only on the highfrequency response of the system. Equation (28) shows clearly that the capacitance developed through the power-law model is dependent on the resistance evident at high-frequency; whereas, equation (11) depends on $R_{\|}$.

\subsection{Free-Machining Steel}

Free-machining 18/8 stainless steel (18 Cr-8Ni), also known as 303 stainless steel, is used when a combination of good corrosion resistance and ease of machining is required. It is used for a variety of parts requiring extensive machining. In an application related to fabrication of heads for computer hard drives, a combination of electrochemical and chemical processing steps were used to increase and monitor the chromium content of the oxide film on the steel. Impedance spectroscopy was used to assess the thickness of the film, and the results were compared to independent values obtained by X-ray photoelectron spectroscopy (XPS).

Samples were prepared by masking the area of interest from other materials of the integrated interconnect circuit built on the stainless steel substrate. The mask was a vinyl tape, $0.132 \mathrm{~mm}$ thick, (3M 471) in which a precision $3 \mathrm{~mm}$ hole was cut. The coupon with applied mask was then sandwiched into a cell as shown in Figure 6 where $1 \mathrm{ml}$ of electrolyte was used to fill the cell. The cell was attached to a PAR 2273 Potentiostat/FRA and impedance measurements were made at the measured opencircuit potential using a $10 \mathrm{mV}$ perturbation. A Ag/ $\mathrm{AgCl}$ reference electrode was used where the tip extends through the Pt counter electrode wire coil. The working electrode connection and working sense were connected on opposite sides of the cell (the coupon extended to either side of the cell).

Impedance data for the steel as received in an electrolyte consisting of $22 \mathrm{~g} / \mathrm{L}$ boric acid with $\mathrm{NaOH}$ added, about $6 \mathrm{~g} / \mathrm{L}$, to bring the $\mathrm{pH}$ to 7.2 , are presented in 


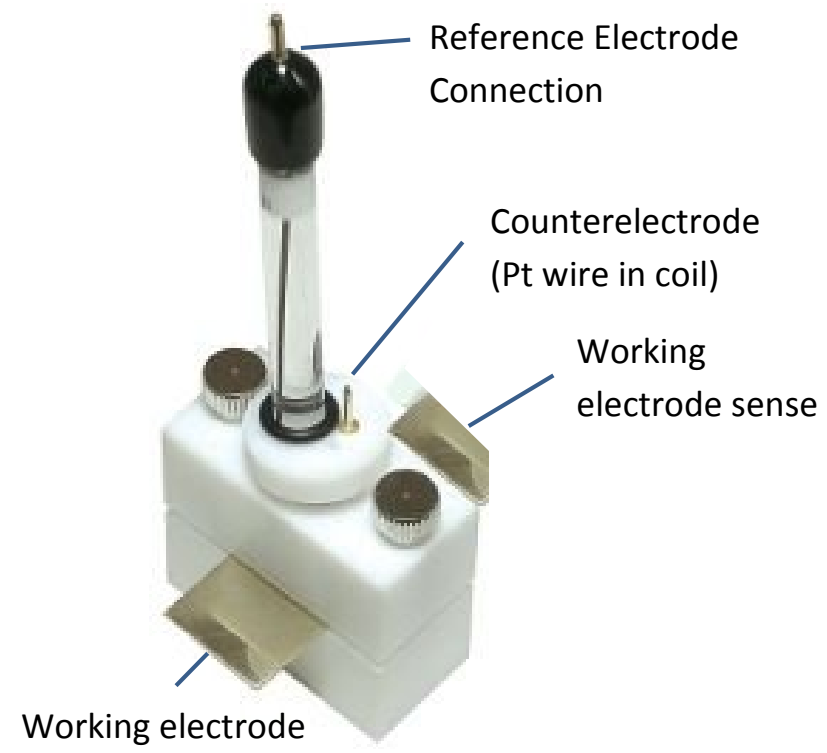

Figure 6: Electrochemical cell designed to evaluate a plate material sandwiched between the two cell blocks. A part of the image was obtained from Bio-Logic (http://www.bio-logic.info/index.html).

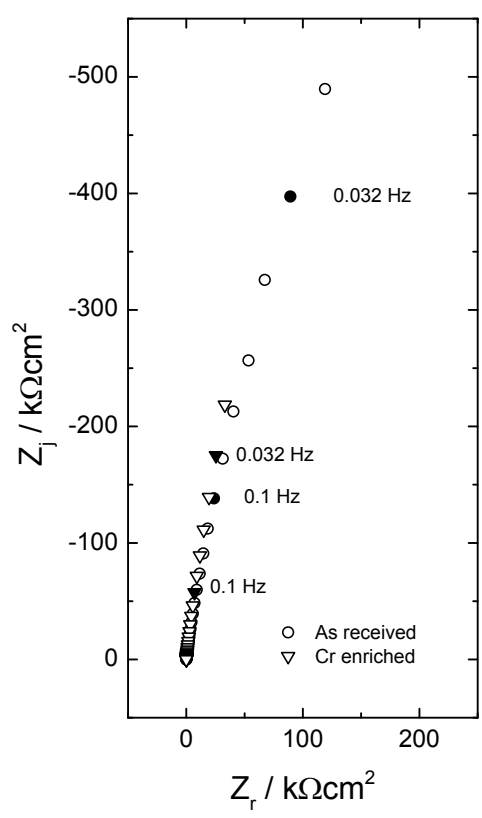

(a)

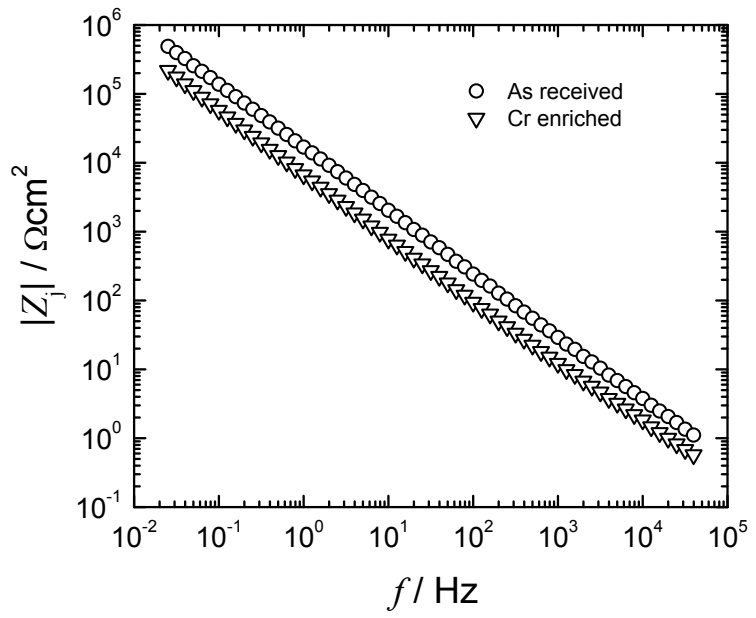

(b)

Figure 7: Impedance data for free-machining 18/8 stainless steel in an electrolyte consisting of $22 \mathrm{~g} / \mathrm{L}$ boric acid with $\mathrm{NaOH}$ added, about $6 \mathrm{~g} / \mathrm{L}$, to bring the $\mathrm{pH}$ to 7.2 (at the edge of buffering region): a) Nyquist plot; and b) imaginary part of the impedance as a function of frequency. Data are presented for the steel in as-received condition and after a proprietary treatment to increase the chromium content of the oxide film. 
Table 3: Regression results for free-machining 18/8 stainless steel in an electrolyte consisting of $22 \mathrm{~g} / \mathrm{L}$ boric acid with $\mathrm{NaOH}$ added to bring the $\mathrm{pH}$ to 7.2.

\begin{tabular}{c|c|c}
\hline & As Received & After Proprietary Treatment \\
\hline$R_{\mathrm{e}}, \Omega \mathrm{cm}^{2}$ & 15.3 & 13.3 \\
$R_{\|}, \mathrm{M} \Omega \mathrm{cm}^{2}$ & 2.33 & 16.8 \\
$\alpha$ & 0.91 & 0.91 \\
$Q, \mu \mathrm{F} / \mathrm{s}^{(1-\alpha)} \mathrm{cm}^{2}$ & 11 & 30.5 \\
\hline$\delta$ by XPS, nm & 6.3 & 2.5 \\
\hline
\end{tabular}

Table 4: Estimations of oxide thickness for free-machining 18/8 stainless steel in an electrolyte consisting of $22 \mathrm{~g} / \mathrm{L}$ boric acid with $\mathrm{NaOH}$ added to bring the pH to 7.2. The steel was in as-received condition, and the oxide thickness was measured by XPS to be $6.3 \mathrm{~nm}$.

\begin{tabular}{l|c|c|c|c}
\hline Approach & Type of Distribution & $C_{\text {eff }}, \mu \mathrm{F} / \mathrm{cm}^{2}$ & $\delta, \mathrm{nm}$ & $100\left(\delta_{\text {EIS }}-\delta_{\text {XPS }}\right) / \delta_{\text {XPS }}$ \\
\hline Eqn. (6) & - & 11 & 0.97 & $-85 \%$ \\
Eqn. (11) & normal & 15 & 0.72 & $-89 \%$ \\
Eqn. (17) & surface & 4.9 & 2.2 & $-65 \%$ \\
Eqn. (27) & normal & 1.8 & 5.9 & $-6 \%$ \\
\hline
\end{tabular}

Figure 7 for the steel in as-received condition and after a proprietary treatment to increase the chromium content of the oxide film. Due to the slight curvature evident in Figure 7(a), the data could not be fit by equation (2); whereas, the data could be fit well by equation (22), represented by Figure 1(b), by equation (23) in parallel with a resistance, represented by Figure 1(d), or by equation (1). As shown in Figure 7(b), the CPE behavior is valid in the entire frequency range and, in particular, at high frequency, which is visible only in this representation. Due to the finite frequency range of the data shown in Figure 7(a), these models could not be distinguished. The results obtained by regression of equation (1) are presented in Table 3.

Approaches for estimation of oxide thickness were compared under the assumption that the dielectric constant of the oxide could be taken as having a value $\epsilon=12 .{ }^{20}$ The parameter $\rho_{\delta}$, used in the power-law model, was assigned a value of $\rho_{\delta}=500 \Omega \mathrm{cm}$. The value $\rho_{\delta}=500 \Omega \mathrm{cm}$ is consistent with the observation of semiconducting properties for the oxide. Using impedance data and a value for the thickness of an oxide film measured by XPS, as reported by Frateur et al. ${ }^{21}$ Hirschorn et al. ${ }^{2}$ found a value of $\rho_{\delta}=450 \Omega \mathrm{cm}$. This value was rounded to $\rho_{\delta}=500 \Omega \mathrm{cm}$ in recognition of the large confidence interval expected for thicknesses measured by XPS, uncertainty in the assumed value for dielectric constant $\epsilon$, and the assumption that the passive film is homogeneous and behaves as a single metal oxide film. The results are presented in Table 4 for steel in the as-received condition and in Table 5 for the steel after chemical treatment. The quantity $100\left(\delta_{\text {EIS }}-\delta_{\text {XPS }}\right) / \delta_{\text {XPS }}$ is presented to show the extent of the agreement between the value for oxide thickness derived from impedance measurements, $\delta_{\mathrm{EIS}}$, and the value obtained from XPS measurements, $\delta_{\mathrm{XPS}}$. For the as received and treated coupons, the thickness obtained from equation (27) is within 
Table 5: Estimations of oxide thickness for free-machining 18/8 stainless steel in an electrolyte consisting of $22 \mathrm{~g} / \mathrm{L}$ boric acid with $\mathrm{NaOH}$ added to bring the pH to 7.2. The steel has undergone a proprietary chemical treatment to increase the chromium content of the oxide. The oxide thickness was measured by XPS to be $2.5 \mathrm{~nm}$.

\begin{tabular}{l|c|c|c|c}
\hline Approach & Type of Distribution & $C_{\text {eff }}, \mu \mathrm{F} / \mathrm{cm}^{2}$ & $\delta, \mathrm{nm}$ & $100\left(\delta_{\text {EIS }}-\delta_{\text {XPS }}\right) / \delta_{\text {XPS }}$ \\
\hline Eqn. (6) & - & 30.5 & 0.35 & $-86 \%$ \\
Eqn. (11) & normal & 59.0 & 0.18 & $-93 \%$ \\
Eqn. (17) & surface & 13.3 & 0.80 & $-68 \%$ \\
Eqn. (27) & normal & 4.0 & 2.7 & $+8 \%$ \\
\hline
\end{tabular}

6 and $8 \%$, respectively, of the values measured by XPS. This is within the expected confidence interval for measurements of oxide thickness by XPS.

The value for film thickness obtained by setting $C=Q$ does not agree with the value obtained by XPS, even though the CPE parameter $\alpha$ had a value of 0.91 , which may be considered to be close to unity. The thicknesses obtained using the characteristic frequency of the impedance (equation (11)) also do not agree with the measured value. The lack of agreement of the values derived from the characteristic frequency of the admittance (equation (17)) with the value obtained by XPS suggests that the CPE behavior cannot be attributed to a surface distribution of time constants. The power-law model which, in contrast to equation (11), extracts information from the high-frequency part of the impedance measurement and is independent of the characteristic frequency, provided excellent agreement with XPS results.

Difficuties with using the characteristic frequency of the impedance, i.e., equation (11), to extract meaningful parameters for oxides were also noted by Huang et al. ${ }^{22}$ Mohammadi et al. ${ }^{23}$ compared thicknesses of passive films on 304 stainless steel derived by use of equations (6), (18), and (11) to independently measured thicknesses. Under assumption that the dielectric constant was equal to 30, they found that the Brug formula for a surface distribution of time constants provided the estimate for film thickness that was closest to the values obtained by ellipsometry. Their ellipsometry measurements indicated that the films were about $2-3 \mathrm{~nm}$ thick, in good agreement with some of the values obtained in the present study by XPS.

\subsection{Martensitic Stainless Steel}

Martensitic stainless steels are mainly used for their excellent mechanical properties. They are, however, relatively sensitive to localized corrosion. The impedance response of a X12CrNiMoV12-3 steel rotating disk electrode was studied in aerated and deaerated neutral electrolytes containing $0.1 \mathrm{M} \mathrm{NaCl}$ and $0.04 \mathrm{M} \mathrm{Na}_{2} \mathrm{SO}_{4}$.

Three cases are presented here. In Cases A and B, the electrolyte was aerated. In Case C, the electrolyte was deaerated by sparging with nitrogen. In Case B, the electrode was first held at a cathodic potential to remove air-formed oxides. Impedance measurements were performed at the open circuit, for an electrode rotation speed of $500 \mathrm{rpm}$, and after different times of immersion, ranging from 2 to 17 hours. ${ }^{24}$ The impedance response after 17 hours of immersion is presented in Figure 8. 


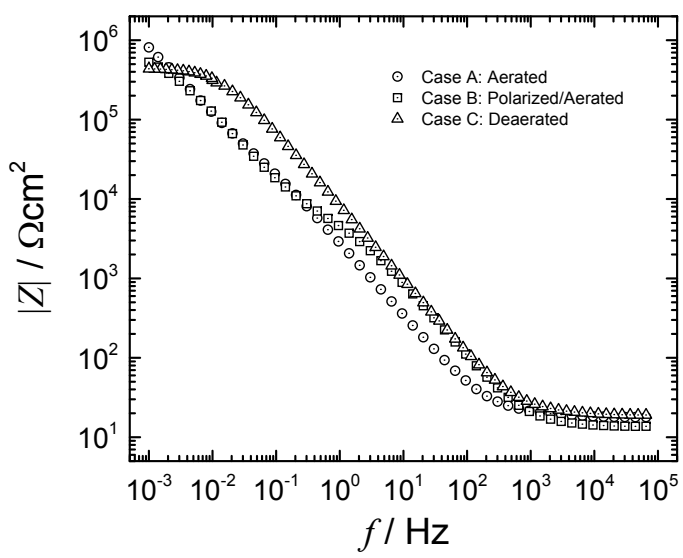

(a)

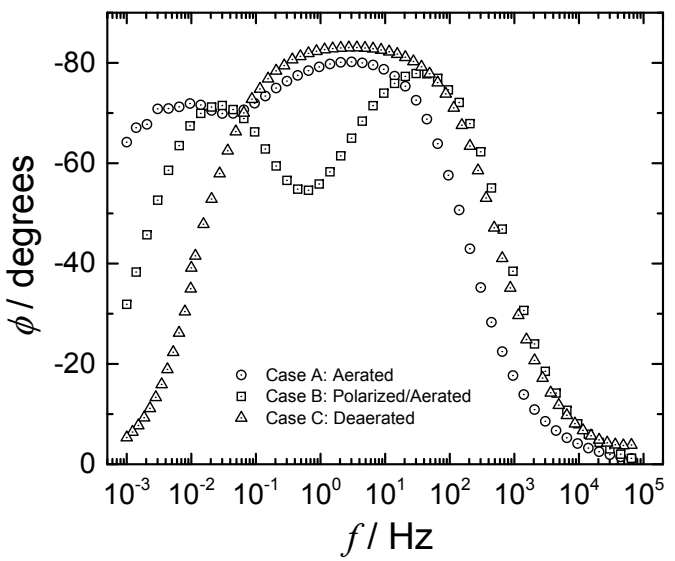

(b)

Figure 8: Bode diagrams for martensitic steel disks rotating at $500 \mathrm{rpm}$ at open circuit after 17 hours of immersion in neutral electrolytes containing $0.1 \mathrm{M} \mathrm{NaCl}$ and $0.04 \mathrm{M} \mathrm{Na}_{2} \mathrm{SO}_{4}$ : a) Magnitude; and b) phase angle. Case A: the electrolyte was aerated; Case B: the electrode was held at a cathodic potential to remove air-formed oxides before being subjected to an aerated medium; and Case C: the electrolyte was deaerated.

For the data collected in deaerated environment (Case C), only one time constant is visible on the impedance diagram, and parameters were obtained by regression of equation (1) in the whole frequency range. For Cases A and B, two time constants appear in Figure 8. The low frequency part of the diagrams corresponds to the charge-transfer process of oxygen reduction, and the high-frequency domain corresponds to the oxide layer. In accordance with the objectives of the present work, only the high-frequency part was analysed by regression of equation (1). The thickness and composition of the layers formed on the steel after 17 hours of immersion were estimated by XPS. The regression and XPS results are presented in Table 6 .

The four approaches for extracting physical information from CPE data were applied to the impedance data to estimate the oxide thickness, and the results are also presented in Table 6 . The parameter $\rho_{\delta}$, used in the power-law model, was assigned a value of $\rho_{\delta}=500 \Omega \mathrm{cm}$ because the oxide on steel has a semiconducting character and can be expected to have properties similar to that of the steel analyzed by Hirschorn et al. ${ }^{2}$ The dielectric constant of the oxide was assigned a value $\epsilon=12$.

For Case B, the film thickness derived by use of the power-law model (equation (27)) increased with immersion time, and the value at 17 hours of immersion was in excellent agreement with the thickness measured independently by XPS. As was seen for the free-machining steel, the thickness values obtained by assumption that $C=Q$, equation (6), by using the formula derived from the characteristic frequency of the impedance, equation (11), and by assuming a surface distribution, equation (17) were significantly smaller than the value obtained from XPS or by use of the power-law model.

A similar result was obtained for Case C, in which the electrolyte was deaerated. The film thickness derived by use of the power-law model decreased with immersion 
Table 6: Regression results reported for a martensitic steel disk rotating at $500 \mathrm{rpm}$ in a neutral electrolyte containing $0.1 \mathrm{M} \mathrm{NaCl}$ and $0.04 \mathrm{M} \mathrm{Na}_{2} \mathrm{SO}_{4} \cdot{ }^{24}$ Case A: the electrolyte was aerated; Case B: the electrode was held at a cathodic potential to remove air-formed oxides before being subjected to an aerated medium; and Case C: the electrolyte was deaerated. The regression values reported here are only those that are used in the analysis.

\begin{tabular}{|c|c|c|c|c|c|c|c|c|c|c|}
\hline \multirow{3}{*}{\multicolumn{2}{|c|}{$\begin{array}{c}\text { Condition } \\
\text { Time } \\
\mathrm{h}\end{array}$}} & \multicolumn{4}{|c|}{ Regression Results } & \multicolumn{5}{|c|}{ Film Thickness, nm } \\
\hline & & \multirow{2}{*}{$\begin{array}{c}R_{\mathrm{e}} \\
\Omega \mathrm{cm}^{2}\end{array}$} & \multirow{2}{*}{$\begin{array}{c}R_{\|} \\
k \Omega \mathrm{cm}^{2}\end{array}$} & \multirow[t]{2}{*}{$\alpha_{\mathrm{ox}}$} & \multirow{2}{*}{$\begin{array}{c}Q_{\mathrm{ox}} \\
\mu \mathrm{F} / \mathrm{s}^{(1-\alpha)} \mathrm{cm}^{2}\end{array}$} & \multicolumn{4}{|c|}{ Approach: Eqn. } & \multirow{2}{*}{$\begin{array}{l}\text { Expt. } \\
\text { XPS }\end{array}$} \\
\hline & & & & & & (6) & $(11)$ & $(17)$ & $(27)$ & \\
\hline \multirow[t]{4}{*}{ A } & 2 & 17.0 & 50 & 0.90 & 90 & 0.12 & 0.10 & 0.24 & 1.0 & - \\
\hline & 6 & 17.2 & 62 & 0.90 & 87 & 0.12 & 0.10 & 0.25 & 1.0 & - \\
\hline & 10 & 17.0 & 76 & 0.90 & 86 & 0.12 & 0.10 & 0.26 & 1.0 & - \\
\hline & 17 & 17.2 & 110 & 0.90 & 76 & 0.14 & 0.11 & 0.29 & 1.2 & 2.8 \\
\hline \multirow[t]{4}{*}{ B } & 2 & 15.6 & 6.1 & 0.91 & 32 & 0.33 & 0.39 & 0.70 & 2.3 & - \\
\hline & 6 & 14.8 & 7.2 & 0.91 & 29 & 0.37 & 0.43 & 0.79 & 2.5 & - \\
\hline & 10 & 14.5 & 7.3 & 0.91 & 27 & 0.39 & 0.46 & 0.85 & 2.7 & - \\
\hline & 17 & 14.2 & 7.7 & 0.91 & 26 & 0.41 & 0.48 & 0.89 & 2.8 & 3.1 \\
\hline \multirow[t]{3}{*}{$\mathrm{C}$} & 6 & 19.8 & 330 & 0.90 & 30 & 0.35 & 0.27 & 0.81 & 3.0 & - \\
\hline & 10 & 20.0 & 388 & 0.91 & 26 & 0.41 & 0.33 & 0.86 & 2.8 & - \\
\hline & 17 & 20.5 & 443 & 0.92 & 23 & 0.46 & 0.38 & 0.90 & 2.5 & 2.5 \\
\hline
\end{tabular}

time, and the value at 17 hours of immersion agreed with the thickness measured by XPS. Again, equations (6), (11), and (17) yielded poor agreement with the independent measure of film thickness.

For Case A, in which the electrolyte was aerated, the power-law model yielded thicknesses on the order of $1 \mathrm{~nm}$. The small thickness, as compared to that calculated for Cases B and C, can be attributed to dissolution of the iron species during immersion in the electrolyte, leading to a decreased film thickness. As a consequence, the oxide film is enriched in chromium oxide and hydroxide, as was confirmed by XPS analysis. $^{24}$ This dissolution process has been reported previously in the literature. ${ }^{25-27}$ The discrepancy between the thickness obtained by the power-law model and the XPS results may be due to the exposure of the sample to air as it was transported from the electrochemical cell to the surface analysis instrumentation. The film thickness could be modified by oxidation of the iron species.

The values for film thickness obtained by setting $C=Q$ (equation (6)) or by using the values derived from the characteristic frequency of the impedance (equation (11)) are clearly much smaller than obtained by XPS. The values derived from the characteristic frequency of the admittance (equation (17)) are also smaller than found by XPS, suggesting that the CPE response cannot be attributed to a surface distribution of time constants. The values for film thickness obtained from equation (27) are in the range of those expected for oxides on steel and, in two cases, were in excellent agreement with results obtained by XPS. It should be noted that, as the interpretation based on the power-law model employs only information obtained at high-frequency, the results obtained are independent of the hypothesis employed to develop the model that accounts for low-frequency behavior. 


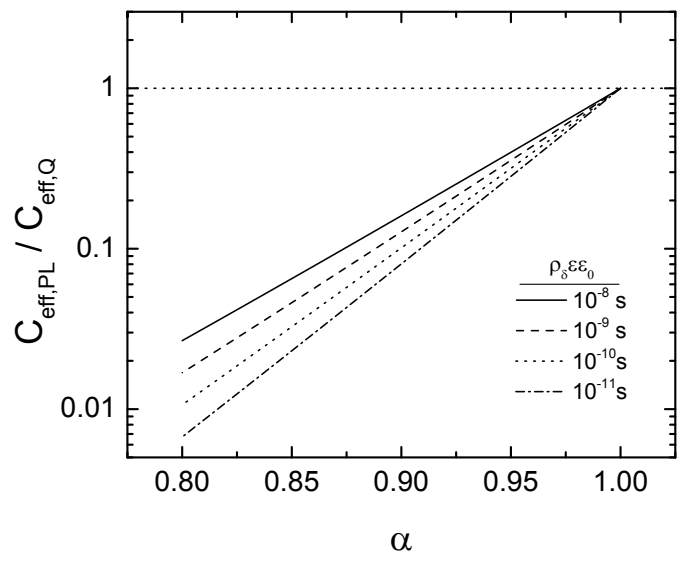

(a)

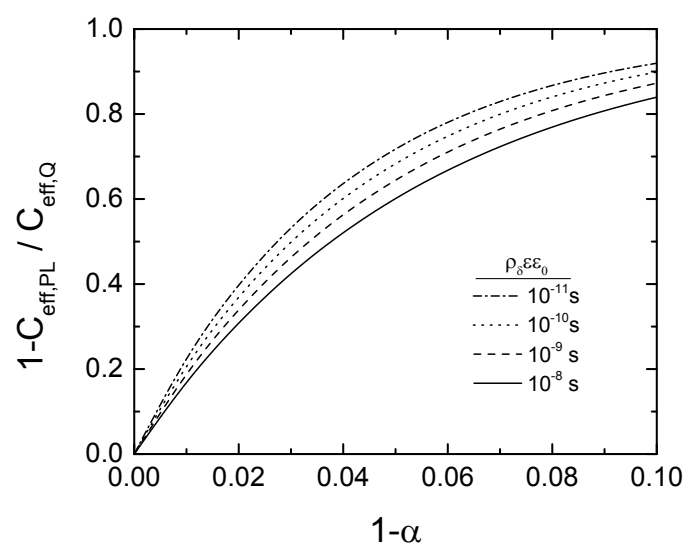

(b)

Figure 9: Correction factor, applicable for a normal distribution of time constants, for the assumption that $C=Q:$ a) $C_{\text {eff,PL }} / C_{\text {eff }, Q}$ as a function of $\alpha$ with $\rho_{\delta} \epsilon \epsilon_{0}$ as a parameter; and b) $1-C_{\mathrm{eff}, \mathrm{PL}} / C_{\mathrm{eff}, Q}$ as a function of $1-\alpha$ with $\rho_{\delta} \epsilon \epsilon_{0}$ as a parameter.

\section{Discussion}

The discussion is presented here in terms of each of the approaches considered: simple substitution, characteristic frequency associated with a normal time-constant distribution, characteristic frequency associated with a surface time-constant distribution, and the power law model.

\subsection{Simple Substitution}

For the two oxides shown in the present work, the assumption $C=Q$ provides poor estimates for physical properties, even though $\alpha$ was larger than 0.9. This result raises the question - under what circumstances may one assume that $C=Q$ ? The evaluation of this question depends on whether the CPE behavior is caused by normal or surface distributions.

\subsubsection{Normal Distribution}

The results presented here show that, for normal distributions, the power-law model provides the most accurate assessment of CPE parameters in terms of physical properties. Thus, for a normal distribution, an appropriate figure of merit would be

$$
\frac{C_{\text {eff,PL }}}{C_{\text {eff }, Q}}=g\left(\rho_{\delta} \epsilon \epsilon_{0}\right)^{1-\alpha}
$$

Equation (39) shows that the accuracy associated with setting $C=Q$ is not simply a function of $\alpha$, but depends as well on other physical properties of the system under study.

The ratio $C_{\text {eff,PL }} / C_{\text {eff, } Q}$ is presented in Figure 9 (a) as a function of $\alpha$ with typical values of $\rho_{\delta} \epsilon \epsilon_{0}$ as a parameter. The corresponding plot of $1-C_{\text {eff,PL }} / C_{\text {eff, } Q}$ is presented in Figure 9(b) as a function of $1-\alpha$. Figure 9(b) emphasizes the behavior near $\alpha=1$. 


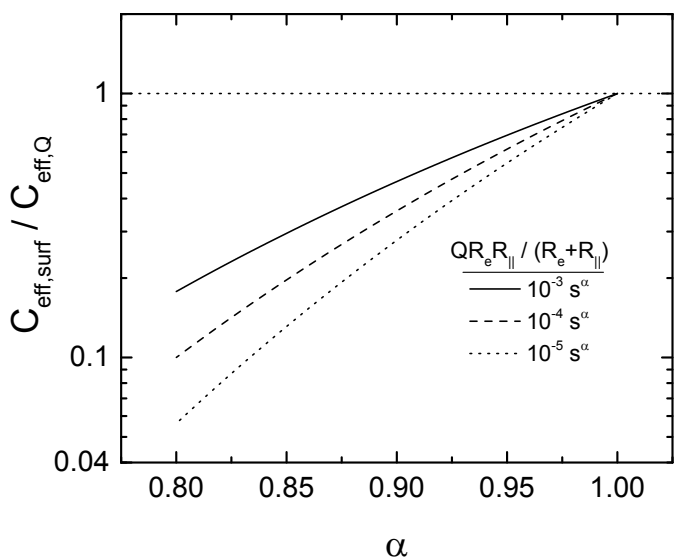

(a)

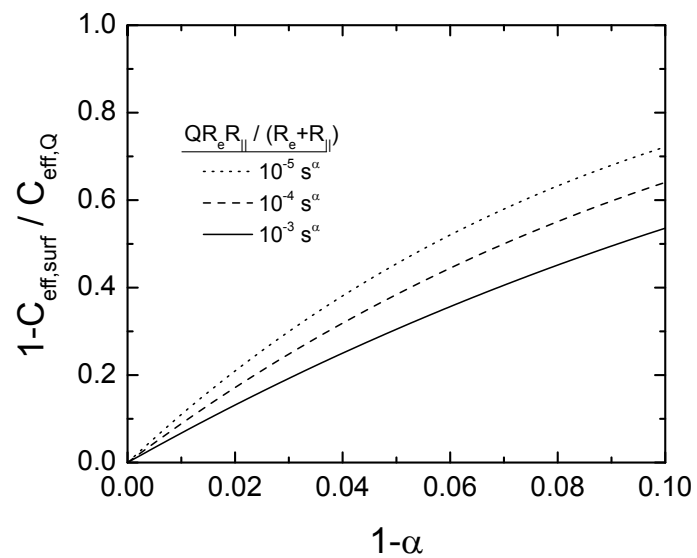

(b)

Figure 10: Correction factor, applicable for a surface distribution of time constants, for the assumption that $C=Q$ : a) $C_{\mathrm{eff}, \text { surf }} / C_{\mathrm{eff}, Q}$ as a function of $\alpha$ with $Q R_{\mathrm{e}} R_{\|} /\left(R_{\mathrm{e}}+\right.$ $\left.R_{\|}\right)$as a parameter; and b) $1-C_{\text {eff,surf }} / C_{\text {eff }, Q}$ as a function of $1-\alpha$ with $Q R_{\mathrm{e}} R_{\|} /\left(R_{\mathrm{e}}+\right.$ $\left.R_{\|}\right)$as a parameter.

For the oxides films treated in the present work, $\rho_{\delta} \epsilon \epsilon_{0}$ has a value of $5 \times 10^{-10} \mathrm{~s}$. The error in using $C_{\text {eff }, Q}$ is 23 percent at $\alpha=0.99$ and 100 percent at $\alpha=0.97$. Thus, the assumption that $C=Q$ should not be used for normal distributions.

\subsubsection{Surface Distribution}

In previous work, Hirschorn et al. ${ }^{9}$ showed that the model developed by Brug et al. ${ }^{5}$ provided a good interpretation for cases where surface time constant distributions gave rise to $\mathrm{CPE}$ behavior. Thus, for a surface distribution, an appropriate figure of merit would be

$$
\frac{C_{\mathrm{eff}, \mathrm{surf}}}{C_{\mathrm{eff}, Q}}=\left(Q \frac{R_{\mathrm{e}} R_{\|}}{R_{\mathrm{e}}+R_{\|}}\right)^{(1-\alpha) / \alpha}
$$

Again, the accuracy associated with setting $C=Q$ is not simply a function of $\alpha$, but depends as well on other physical properties of the system under study.

The factor $C_{\text {eff,surf }} / C_{\text {eff, } Q}$ is presented in Figure 10(a) as a function of $\alpha$ with the quantity $Q R_{\mathrm{e}} R_{\|} /\left(R_{\mathrm{e}}+R_{\|}\right)$as a parameter. To emphasize the behavior near $\alpha=1$, the quantity $1-C_{\text {eff,surf }} / C_{\text {eff, } Q}$ is presented in Figure 10 (b) as a function of $1-\alpha$. For $R_{\mathrm{e}}=10 \Omega \mathrm{cm}^{2}, Q=10^{-5} \mathrm{Fs}^{\alpha-1} / \mathrm{cm}^{2}$, and $R_{\|}>R_{\mathrm{e}}$, the parameter $Q R_{\mathrm{e}} R_{\|} /\left(R_{\mathrm{e}}+R_{\|}\right)$ has a value near $10^{-4} \mathrm{~s}^{\alpha}$. For $Q R_{\mathrm{e}} R_{\|} /\left(R_{\mathrm{e}}+R_{\|}\right)=10^{-4} \mathrm{~s}^{\alpha}$ and at a value $\alpha=0.93$, $C_{\text {eff, } Q}$ will be a factor of 2 larger than $C_{\text {eff,surf }}$. The error will be near 10 percent at $\alpha=0.99$. A comparison of Figures $9(\mathrm{~b})$ and $10(\mathrm{~b})$ shows that the error in assuming $C=Q$ for surface distributions is smaller at a given value of $\alpha$ than it is for normal distributions. However, the error is sufficiently large that the assumption that $C=Q$ is not recommended for surface distributions. 


\subsection{Characteristic Frequency Associated with a Normal Distribution}

The results show that the effective capacitance derived from the characteristic frequency of the impedance does not provide good estimates for physical properties because the resistance associated with the characteristic frequency is independent of the dielectric properties of the film. The result is that the effective capacitance is too large. When used to evaluate film thickness, the value obtained is an order of magnitude too small, giving, as shown in Table 5 , a thickness of $0.18 \mathrm{~nm}$ for a film with an independently measured thickness of $2.5 \mathrm{~nm}$. For an oxide with independently measured thickness of $6.3 \mathrm{~nm}$, a value of $0.72 \mathrm{~nm}$ was found, as reported in Table 4. Similar results were found for martensitic steel, as shown in Table 6. Application to the skin data yielded an incorrect prediction of the impact that perforation of the skin would have on the characteristic frequency. As discussed previously, the effective capacitance derived from the characteristic frequency of the impedance should not be used to obtain estimates for physical properties.

\subsection{Characteristic Frequency Associated with a Surface Distribution}

While the CPE response of the systems studied in the present work could, in principle, have been attributed to a surface time-constant distribution, the effective capacitance derived from the characteristic frequency of the admittance did not adequately describe the results. Application of the surface-distribution model to the skin data yielded a result that perforation of the skin would have no impact on the characteristic frequency. This result was seen because the effective capacitance depends on only $R_{\mathrm{e}}$ when $R_{\|}>>R_{\mathrm{e}}$, and $R_{\mathrm{e}}$ is not associated with film properties. The values obtained for the oxides on steel, however, were more reasonable than the values obtained from the characteristic frequency of the impedance. For example, the value for oxide thickness obtained from the characteristic frequency of the admittance, reported in Table 4, was $2.2 \mathrm{~nm}$ as compared to $0.72 \mathrm{~nm}$ obtained from the characteristic frequency of the impedance. As illustrated in the present work, even if the characteristic frequency associated with a surface distribution yields more reasonable values, the values may still be incorrect.

\subsection{Power-Law Distribution}

As shown in Figure 5, the power law approach yielded the correct frequency shift for the impedance of skin associated with a hole in the skin. As shown in Tables 4, 5 , and 6 , the power-law approach yielded values for the thickness of oxides in good agreement with the independently measured values. This agreement was particularly striking when compared to the poor agreement obtained by the other approaches discussed here. The results presented here show that the power-law model ${ }^{1,2}$ for $\mathrm{CPE}$ behavior provides a powerful approach for interpretation of CPE parameters in terms of physical properties such as film thickness. 


\section{Conclusions}

The CPE parameters $Q$ and $\alpha$ may be interpreted in terms of such physical properties as film thickness and dielectric constant. The interpretation depends on the nature of the associated time constant distribution. In the case of surface distributions, the formulae provided by Brug et al. ${ }^{5}$ (Equations (17) and (18)) are recommended; whereas, in the case of normal distributions, the use of the power-law model ${ }^{1,2}$ is preferred.

The power-law model for normal distribution of resistivity presented by Hirschorn et al. ${ }^{1,2}$ provided an accurate means for evaluating the impedance data presented in this work for oxides and was consistent with experimental observations for the impedance of human skin.

The effective capacitance derived from the characteristic frequency of the impedance does not provide good estimates for physical properties. This work shows that the capacitance depends on the high-frequency impedance response and is independent of the low-frequency asymptote $Z_{\mathrm{f}}(0)$. The effective capacitance derived from the characteristic frequency of the impedance should not be used to determine the dielectric constant or the film thickness.

While surface distributions may also give rise to CPE behavior, the parameter values obtained from the characteristic frequency of the admittance did not agree with the results reported here. The assumption that the effective capacitance may be assigned the numerical value of $Q$ also provides poor estimates for physical properties. Use of this assumption is discouraged whenever a CPE is used to improve the fit.

\section{Acknowledgements}

The authors gratefully acknowledge the support of the National Institute of Occupational Safety and Health Award No. R01 OH007493 (Bunge, White, and Orazem); Hutchinson Technology, USA (Riemer); and the partners of the ARCAM project, especially Ratier-Figeac and Aubert \& Duval, France (Pébère and Marcelin). 


\section{References}

1. B. Hirschorn, M. E. Orazem, B. Tribollet, V. Vivier, I. Frateur, and M. Musiani, J. Electrochem. Soc., 157 (2010) C452-C457.

2. B. Hirschorn, M. E. Orazem, B. Tribollet, V. Vivier, I. Frateur, and M. Musiani, J. Electrochem. Soc., 157 (2010) C458-C463.

3. M. E. Orazem and B. Tribollet, Electrochemical Impedance Spectroscopy (Hoboken, NJ: John Wiley \& Sons, 2008).

4. J.-B. Jorcin, M. E. Orazem, N. Pébère, and B. Tribollet, Electrochim. Acta, 51 (2006) 1473-1479.

5. G. J. Brug, A. L. G. van den Eeden, M. Sluyters-Rehbach, and J. H. Sluyters, J. Electroanal. Chem., 176 (1984) 275-295.

6. C. H. Hsu and F. Mansfeld, Corrosion, 57 (2001) 747-748.

7. S. Y. Oh and R. H. Guy, J. Kor. Pharm. Sci., 24 (1994) S41-S47.

8. S. Y. Oh and R. H. Guy, J. Kor. Pharm. Sci., 24 (1994) 281-287.

9. B. Hirschorn, M. E. Orazem, B. Tribollet, V. Vivier, I. Frateur, and M. Musiani, Electrochim. Acta, 55 (2010) 6218-6227.

10. E. Chassaing, B. Sapoval, G. Daccord, and R. Lenormand, J. Electroanal. Chem., 279 (1990) 67-78.

11. E. D. Bidóia, L. O. S. Bulhões, and R. C. Rocha-Filho, Electrochim. Acta, 39 (1994) 763-769.

12. P. Agarwal, M. E. Orazem, and L. H. García-Rubio, J. Electrochem. Soc., 139 (1992) 1917-1927.

13. P. Agarwal, O. D. Crisalle, M. E. Orazem, and L. H. García-Rubio, J. Electrochem. Soc., 142 (1995) 4149-4158.

14. M. Musiani, M. E. Orazem, N. Pébère, B. Tribollet, and V. Vivier, J. Electrochem. Soc., 158 (2011) C424-C428.

15. S. Amand, M. Musiani, M. E. Orazem, N. Pébère, B. Tribollet, and V. Vivier, Electrochim. Acta, 87 (2012) 693-700.

16. E. A. White, Characterization of the Skin Barrier to Chemical Permeation by Impedance Spectroscopy, Ph.D. dissertation, Colorado School of Mines, Golden, Colorado (2011).

17. E. A. White, M. E. Orazem, , and A. L. Bunge, J. Electrochem. Soc., 159 (2012) G161-G165. 
18. E. A. White, M. E. Orazem, and A. L. Bunge, Pharmaceutical Research, (2013) under review.

19. E. A. White, M. E. Orazem, and A. L. Bunge, Pharmaceutical Research, (2013) under review.

20. W. M. Haynes, editor, CRC Handbook of Chemistry and Physics, 93rd edition (New York, New York: Taylor and Francis Group, LLC, 2012).

21. I. Frateur, L. Lartundo-Rojas, C. Méthivier, A. Galtayries, and P. Marcus, Electrochim. Acta, 51 (2006) 1550-1557.

22. Y. Huang, H. Shih, and F. Mansfeld, Mater. Corros., 61 (2010) 302-305.

23. F. Mohammadi, T. Nickchi, M. Attar, and A. Alfantazi, Electrochimica Acta, 56 (2011) 8727-8733.

24. S. Marcelin, N. Pébère, and S. Régnier, Electrochim. Acta, (2012) in press.

25. K. Asami and K. Hashimoto, Corros. Sci., 19 (1979) 1007-1017.

26. R. Kirchheim, B. Heine, H. Fischmeister, S. Hofmann, H. Knote, and U. Stolz, Corros. Sci., 29 (1989) 899-917.

27. R.-H. Jung, H. Tsuchiya, and S. Fujimoto, Corros. Sci., 58 (2012) 62-68. 


\section{List of Symbols}

\section{Roman}

\begin{tabular}{|c|c|}
\hline$C_{\text {eff }}$ & effective capacitance, $\mathrm{F} / \mathrm{cm}^{2}$ \\
\hline$C_{\text {eff }, \mathrm{OG}}$ & effective capacitance, model of $\mathrm{Oh}$ and Guy, $\mathrm{F} / \mathrm{cm}^{2}$ \\
\hline$C_{\text {eff,Q }}$ & effective capacitance, simple substitution, $\mathrm{F} / \mathrm{cm}^{2}$ \\
\hline$C_{\text {eff,surf }}$ & effective capacitance, surface distribution, $\mathrm{F} / \mathrm{cm}^{2}$ \\
\hline$C_{\text {eff,PL }}$ & effective capacitance, power-law distribution, $\mathrm{F} / \mathrm{cm}^{2}$ \\
\hline$C_{\text {skin }}$ & capacitance of skin, $\mathrm{F} / \mathrm{cm}^{2}$ \\
\hline$f$ & frequency, $\mathrm{Hz}$ \\
\hline$f_{\mathrm{c}}$ & characteristic frequency, $\mathrm{Hz}$ \\
\hline$f_{\text {c,norm }}$ & characteristic frequency for normal distribution, $\mathrm{Hz}$ \\
\hline$f_{\mathrm{c}, \text { surf }}$ & characteristic frequency for surface distribution, $\mathrm{Hz}$ \\
\hline$f_{\text {after }}$ & characteristic frequency after skin was pierced, $\mathrm{Hz}$ \\
\hline$f_{\text {before }}$ & characteristic frequency before skin was pierced, $\mathrm{Hz}$ \\
\hline$g$ & numerical function given by equation (25) \\
\hline j & imaginary number, $\mathrm{j}=\sqrt{-1}$ \\
\hline$K_{\text {norm }}$ & dimensionless frequency for a normal distribution, equation (8) \\
\hline$K_{\text {surf }}$ & dimensionless frequency for a normal distribution, equation (14) \\
\hline$Q$ & CPE coefficient, $\mathrm{F} / \mathrm{s}^{1-\alpha} \mathrm{cm}^{2}$ or $\mathrm{s}^{\alpha} / \Omega \mathrm{cm}^{2}$ \\
\hline$Q_{\text {ox }}$ & CPE coefficient for an oxide layer, $\mathrm{F} / \mathrm{s}^{1-\alpha} \mathrm{cm}^{2}$ or $\mathrm{s}^{\alpha} / \Omega \mathrm{cm}^{2}$ \\
\hline$R_{\|}$ & parallel resistance, $\Omega \mathrm{cm}^{2}$ \\
\hline$R_{\mathrm{e}}$ & electrolyte or ohmic resistance, $\Omega \mathrm{cm}^{2}$ \\
\hline$R_{\mathrm{eff}}$ & effective resistance, see equation $(31), \Omega \mathrm{cm}^{2}$ \\
\hline$R_{\text {skin }}$ & skin resistance, $\Omega \mathrm{cm}^{2}$ \\
\hline$R_{\text {hole }}$ & resistance associated with hole in skin, $\Omega \mathrm{cm}^{2}$ \\
\hline$R_{\text {before }}$ & effective resistance of skin before it was pierced, $\Omega \mathrm{cm}^{2}$ \\
\hline$R_{\text {after }}$ & effective resistance of skin after it was pierced, $\Omega \mathrm{cm}^{2}$ \\
\hline$Y$ & admittance, $Y=1 / Z,\left(\Omega \mathrm{cm}^{2}\right)^{-1}$ \\
\hline$Z$ & impedance, $\Omega \mathrm{cm}^{2}$ \\
\hline$Z_{\mathrm{f}}(f)$ & impedance for a power-law model, see equations $(21)-(23), \Omega \mathrm{cm}^{2}$ \\
\hline
\end{tabular}

\section{Greek}

$\alpha \quad$ CPE exponent, dimensionless

$\alpha_{\mathrm{ox}} \quad$ CPE exponent for an oxide layer, dimensionless

$\gamma \quad$ exponent in the power-law model, dimensionless

$\delta \quad$ film thickness, cm

$\delta_{\text {EIS }} \quad$ film thickness determined by EIS, cm

$\delta_{\mathrm{XPS}} \quad$ film thickness determined by XPS, $\mathrm{cm}$

$\epsilon \quad$ dielectric constant, dimensionless

$\epsilon_{0} \quad$ permittivity of vacuum, $8.8542 \times 10^{-14} \mathrm{~F} / \mathrm{cm}$

$\theta_{\mathrm{c}, \text { norm }} \quad$ phase angle at the characteristic frequency $f_{\mathrm{c}, \text { norm }}$, radian

$\zeta \quad$ dimensionless position, $\zeta=y / \delta$

$\pi \quad$ mathematical constant, $\pi=3.14159265358979323846 \ldots$, dimensionless 
$\rho$

$\rho_{\delta}$

$\rho_{0}$

resistivity, $\Omega \mathrm{cm}$

film resistivity at the film-electrolyte interface, $\Omega \mathrm{cm}$

film resistivity at the film-metal interface, $\Omega \mathrm{cm}$ 


\section{$7 \quad$ List of Figures}

1 Hierarchy of impedance models based on the power-law model: ${ }^{1,2}$ a) circuit consisting of a resistance in parallel with the general power-law model expressed as equation (22); b) circuit resulting when $R_{\|}$is much larger than the zero-frequency limit of equation (22); c) Nyquist representation of the asymmetric impedance resulting from circuit b; d) circuit resulting when $R_{\|}$is much smaller than the zero-frequency limit of equation (22), thus allowing equation (22) to be replaced by equation (23); and e) Nyquist representation of the symmetric impedance

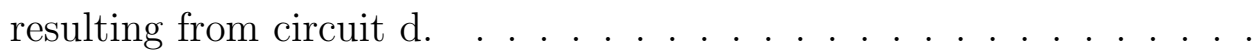

2 Schematic representation of the measurement of skin impedance: a) four-electrode measurement with intact piece of skin; and b) fourelectrode measurement with skin punctured by a needle. . . . . . . .

3 Impedance response for a representative piece of skin: a) Nyquist plot; b) real part of the impedance as a function of frequency; and c) imaginary part of the impedance as a function of frequency. . . . . . . . .

4 Electrical circuits used to fit the data shown in Figure 3: a) intact piece of skin; and b) punctured by a needle. The term $R_{\mathrm{e}}$ accounts for electrolyte resistance on both sides of the skin. . . . . . . . . .

5 A test of the hypotheses that the capacitance of the skin can be obtained from the characteristic frequency $f_{c, n o r m}$, given as equation (11), and from the power-law distribution of resistivity, given as equation (27): $\square$ test of equation (34); $\bigcirc$ test of equation (38). . . . . . . . .

6 Electrochemical cell designed to evaluate a plate material sandwiched between the two cell blocks. A part of the image was obtained from Bio-Logic (http://www.bio-logic.info/index.html). . . . . . . . . .

$7 \quad$ Impedance data for free-machining 18/8 stainless steel in an electrolyte consisting of $22 \mathrm{~g} / \mathrm{L}$ boric acid with $\mathrm{NaOH}$ added, about $6 \mathrm{~g} / \mathrm{L}$, to bring the $\mathrm{pH}$ to 7.2 (at the edge of buffering region): a) Nyquist plot; and b) imaginary part of the impedance as a function of frequency. Data are presented for the steel in as-received condition and after a proprietary treatment to increase the chromium content of the oxide film. . . . .

8 Bode diagrams for martensitic steel disks rotating at $500 \mathrm{rpm}$ at open circuit after 17 hours of immersion in neutral electrolytes containing $0.1 \mathrm{M} \mathrm{NaCl}$ and $0.04 \mathrm{M} \mathrm{Na}_{2} \mathrm{SO}_{4}$ : a) Magnitude; and b) phase angle. Case A: the electrolyte was aerated; Case B: the electrode was held at a cathodic potential to remove air-formed oxides before being subjected to an aerated medium; and Case C: the electrolyte was deaerated. 
9 Correction factor, applicable for a normal distribution of time constants, for the assumption that $C=Q$ : a) $C_{\mathrm{eff}, \mathrm{PL}} / C_{\mathrm{eff}, Q}$ as a function of $\alpha$ with $\rho_{\delta} \epsilon \epsilon_{0}$ as a parameter; and b) $1-C_{\text {eff,PL }} / C_{\text {eff, } Q}$ as a function of $1-\alpha$ with $\rho_{\delta} \epsilon \epsilon_{0}$ as a parameter. . . . . . . . . . . . .

10 Correction factor, applicable for a surface distribution of time constants, for the assumption that $C=Q$ : a) $C_{\text {eff,surf }} / C_{\text {eff, } Q}$ as a function of $\alpha$ with $Q R_{\mathrm{e}} R_{\|} /\left(R_{\mathrm{e}}+R_{\|}\right)$as a parameter; and b) $1-C_{\mathrm{eff}, \text { surf }} / C_{\mathrm{eff}, Q}$ as a function of $1-\alpha$ with $Q R_{\mathrm{e}} R_{\|} /\left(R_{\mathrm{e}}+R_{\|}\right)$as a parameter. . . . . 


\section{List of Tables}

1 Approaches used in the present work to interpret CPE impedance response for film-covered electrodes and human skin. . . . . . . . . .

2 Regression results for the impedance of skin before and after being pierced by a needle. The number of digits given in the regression results are consistent with the corresponding confidence interval. . .

3 Regression results for free-machining 18/8 stainless steel in an electrolyte consisting of $22 \mathrm{~g} / \mathrm{L}$ boric acid with $\mathrm{NaOH}$ added to bring the $\mathrm{pH}$ to $7.2 \ldots \ldots \ldots \ldots \ldots \ldots \ldots \ldots$

4 Estimations of oxide thickness for free-machining 18/8 stainless steel in an electrolyte consisting of $22 \mathrm{~g} / \mathrm{L}$ boric acid with $\mathrm{NaOH}$ added to bring the $\mathrm{pH}$ to 7.2 . The steel was in as-received condition, and the oxide thickness was measured by XPS to be $6.3 \mathrm{~nm} . \ldots \ldots \ldots$.

5 Estimations of oxide thickness for free-machining 18/8 stainless steel in an electrolyte consisting of $22 \mathrm{~g} / \mathrm{L}$ boric acid with $\mathrm{NaOH}$ added to bring the $\mathrm{pH}$ to 7.2 . The steel has undergone a proprietary chemical treatment to increase the chromium content of the oxide. The oxide thickness was measured by XPS to be $2.5 \mathrm{~nm}$. . . . . . . . .

6 Regression results reported for a martensitic steel disk rotating at $500 \mathrm{rpm}$ in a neutral electrolyte containing $0.1 \mathrm{M} \mathrm{NaCl}$ and $0.04 \mathrm{M}$ $\mathrm{Na}_{2} \mathrm{SO}_{4} \cdot{ }^{24}$ Case A: the electrolyte was aerated; Case B: the electrode was held at a cathodic potential to remove air-formed oxides before being subjected to an aerated medium; and Case C: the electrolyte was deaerated. The regression values reported here are only those that are used in the analysis. . . . . . . . . . . . . . . 